\title{
First isolation and genotyping of Bartonella henselae from a cat living with a patient with cat scratch disease in Southeast Europe
}

\author{
Maja Stepanić, Sanja Duvnjak, Irena Reil, Silvio Špičić, Gordan Kompes and Relja Beck (1)
}

\begin{abstract}
Background: The bacterial genus Bartonella is distributed worldwide and poses a public health risk. Cat-scratch disease caused by B. henselae in Croatia was first described in 1957. It is present throughout the country: a survey of serum samples from 268 Croatian patients with lymphadenopathy showed that $37.7 \%$ had IgG antibodies. Despite this prevalence, we are unaware of reports of Bartonella culturing from infected humans or cats in Croatia or elsewhere in southeast Europe.

Case presentation: Here we describe the diagnosis of a 12-year-old child with lymphadenopathy in Croatia with cat-scratch disease based on antibody detection and clinical signs, and the subsequent culturing and genotyping of B.henselae from the cat's blood. The $B$. henselae isolate was grown on different blood agar plates and its identity was confirmed based on polymerase chain reaction (PCR) amplification of 165 ribosomal deoxyribonucleic acid (16S rDNA) and sequencing. Multi-locus sequence typing (MLST) identified the strain genotype as sequence type 5, commonly found zoonotic $B$. henselae strain in cats. The child recovered after azithromycin therapy, and B. henselae in the cat was eliminated within three months after doxycycline treatment.

Conclusions: This is, to our knowledge, the first report of B. henselae culturing and MLST-based genotyping from cat's blood in southeast Europe. Our ability to detect $B$. henselae in blood through culturing but not PCR suggests that the prevalence of infected cats with low bacteremia is very high, suggesting the need to develop faster, more sensitive detection assays.
\end{abstract}

Keywords: Cat-scratch disease, Bartonella henselae, Child, Cat, Culture, Genotyping, MLST, Croatia

\section{Background}

The bacterial genus Bartonella is distributed worldwide and poses a public health risk [1]. More than 20 species cause infections in specific mammalian reservoir hosts; Bartonella henselae, for example, is one of the most frequent causes of zoonoses acquired from companion animals in industrialized countries. B. henselae is a pleomorphic, aerobic, Gram-negative bacterium that causes cat-scratch disease, which involves chronic lymphadenopathy and affects predominantly children and adolescents [2]. Domestic cats, especially young cats and

\footnotetext{
* Correspondence: relja.beck@gmail.com

Department for Bacteriology and Parasitology, Croatian Veterinary Institute, Savska cesta 143, 10000 Zagreb, Croatia
}

kittens, are the primary reservoirs of $B$. henselae; up to $40 \%$ of domestic cats may be infected, and infections can be difficult to detect because no clinical signs may be observed even more than one year after infection [3]. Cats can infect humans directly with $B$. henselae through scratching and biting $[1,2,4]$ or licking. On rare occasions, humans can be infected through bites of Ctenocephalides felis, a cat flea [1] that transmits B. henselae within cat populations [5].

Cat-scratch disease in Croatia was first described in 1957 [6], and since then only a few cases have been reported in the country. These cases were atypical because the clinical signs did not include peripheral lymphadenopathy but rather pancreatic duodenal lymphadenitis,

(c) The Author(s). 2019 Open Access This article is distributed under the terms of the Creative Commons Attribution 4.0 International License (http://creativecommons.org/licenses/by/4.0/), which permits unrestricted use, distribution, and 
fever, and abdominal pain [7] or osteomyelitis of the right humerus [8]. The presence of $B$. henselae in these patients was deduced from the clinical presentation, epidemiological history and presence of anti- $B$. henselae antibodies based on an indirect immunofluorescence assay (IFA). B. henselae is likely to be present throughout the country, since a survey of serum samples from 268 Croatian patients with lymphadenopathy showed that $37.7 \%$ patients had IgG antibodies against B. henselae [9]. Over a quarter of patients $(28.3 \%)$ in that study had IgM antibodies, indicating acute infection. Another study in Croatia showed even higher prevalence of IgG antibodies among healthy adults (31 of 54,57.4\%) and healthy children (19 of 46, 41.3\%) [6]. Despite this prevalence, we are unaware of reports of Bartonella sp. culturing from infected humans or cats in Croatia or elsewhere in southeast Europe.

In the absence of a consensus standard for diagnosing cat-scratch disease $[10,11]$, the best initial diagnostic tests are considered to be serological methods, such as indirect fluorescence or enzyme-linked immunosorbent assay [12], while the gold standard is culturing Bartonella sp. from the blood or tissues of infected humans or cats [13-16], followed by molecular characterization $[15,16]$. However, culturing Bartonella sp. from humans and animals remains challenging [16-19] and has yet to be optimized $[19,20]$.

Here we describe the culture and genotyping of $B$. henselae from cat's blood in Croatia, which appears to be the first such report from this country and, more broadly, from southeast Europe. The bacterium was cultured on various agar plates, and the strain was identified using multi-locus sequence typing (MLST).

\section{Case presentation}

A12-year-old boy living in Zagreb, Croatia presented at a large pediatric clinic in the Croatian capital of Zagreb with acute enlargement of a regional lymph nodes. He was afebrile and reported pain in the axillar and antebrachial regions of the left arm that had persisted for the preceding three days. Palpation revealed a painful formation measuring approximately $1 \times 1.5 \mathrm{~cm}$ in medial on the lower third of the left upper arm. A few smaller lymph nodes, the largest being $1 \mathrm{~cm}$, were palpable in the left axillae. The patient did not show or report any other clinical signs. All haematological and biochemical parameters were within physiological ranges, including CRP. Cat-scratch disease was suspected based on anamnesis and clinical findings. Blood was taken for serological testing, and a 5-day regimen of azithromycin (500 mg/day) was prescribed. Ultrasonography of the left axillae and upper arm showed lymphadenopathy typical of cat-scratch disease. Ultrasonography performed at a private clinic revealed approximately 10 smaller lymph nodes and a few larger ones (17-27 $\mathrm{mm}$ ) showing homogeneous cortex thickness on the left and no obvious differences from the contralateral region. IFAs were performed using a commercial kit (Focus Diagnostics, USA) in the Department of Clinical Microbiology, University Hospital for Infectious Diseases "Dr Fran Mihaljević" (Zagreb, Croatia), and the assays revealed a titer of 1:512 for IgG antibodies against $B$. henselae and 1:128 for IgG antibodies against B. quintana (positivity defined as $\geq 1: 64$ according to the manufacturer's instructions). The assays were negative for IgM antibodies against both bacteria. Following azithromycin treatment, the patient showed improved status, no pain, and normal-sized lymph nodes in the left upper arm.

The patient's parents indicated that they owned one cat and one dog, and that the patient played frequently with the cat. The cat was an apparently healthy, 10-month-old female British shorthair that lived primarily indoors but had free access to a yard; the cat had a history of flea infestation. When a diagnosis of cat-scratch disease was suspected, a sample of the cat's blood was collected at a private veterinary clinic and delivered to the Croatian Veterinary Institute for analysis. Upon isolation of $B$. henselae from the blood (see below), the cat was treated for 3 weeks with doxycycline $(10 \mathrm{mg} / \mathrm{kg}$ body weight $\mathrm{p} / \mathrm{o}$ every $12 \mathrm{~h})[21,22]$, and the patient's parents were advised to protect the cat against ectoparasites.

Both when a diagnosis of cat-scratch disease was suspected and again three months later (following doxycycline treatment), cat's blood was collected in K2-EDTA tubes (Vacuette, Greiner) and stored overnight at $-18{ }^{\circ} \mathrm{C}$ to lyse erythrocytes and release bacteria. The frozen blood was thawed at room temperature, and aliquots $(200 \mu \mathrm{L})$ were plated in duplicate onto Tryptic soy agar with $5 \%$ defibrinated sheep blood (TSA) and Brain heart agar with $5 \%$ defibrinated rabbit blood $(\mathrm{BH})$. Both agar bases were purchased from Merck (Darmstadt, Germany) and used to prepare "ready-to-use" plates. Blood was inoculated onto the plates by simultaneously tilting them at a 45-degree angle and rotating them, allowing the blood to flow across the agar without the need for an inoculating loop or mechanical streaking $[23,24]$. The plates were then incubated, agar side down, at $37^{\circ} \mathrm{C}$ in a humidified atmosphere of $8 \% \mathrm{CO}_{2}[19,25]$. At three days after inoculation, plates were inverted to sit agar side up. At six days after inoculation, single colonies from each type of plate were picked for molecular analysis (see next section). At the same time, single colonies from two TSA plates were subcultured onto two fresh TSA plates, while single colonies from one $\mathrm{BH}$ plate were subcultured onto a single fresh $\mathrm{BH}$ plate. Cat's blood after doxycycline treatment was plated onto two fresh TSA and BH plates. Subcultured and plates inoculated after doxycycline treatment were incubated 
under the same conditions as the first set of plates. Colonies from plates that were subsequently identified as Bartonella spp. by PCR were stored at $-80^{\circ} \mathrm{C}$ in Brucella broth supplemented with $10 \%$ glycerol $(v / v)$ [26].

DNA was extracted from $200 \mu$ EDTA blood and from six cultures using the QIAcube automated DNA isolation system and QiaAmp DNAmini QIAcube Kit, according to the manufacturer's instructions for blood and tissue (Qiagen, Hilden, Germany). In order to determine whether isolates belonged to the genus Bartonella, DNA from six culture isolates were used as template in conventional PCR targeting 16S rRNA (16S-R as forward primer: F 5'-GCC YCC TTG CGG TTA GCA CAG CA-3' and P24Emod as reverse primer: $\mathrm{R} 5^{\prime}{ }^{\prime}$-CCT TCA GTT MGG CTG GAT C-3') as well as the intergenic transcribed spacer between the $16 \mathrm{~S}$ and $23 \mathrm{~S}$ rRNA genes (Bart/16-23F as forward primer: 5' ${ }^{\prime}$ TTG ATA AGC GTG AGG TCG GAG G-3' and Bart/16-23R as reverse primer: 5' $-\mathrm{CAA}$ AGC AGG TGC TCT CCC AG-3') [27].

The DNA extracted from cultures served as template for MLST at the following nine loci in housekeeping genes [28]: 16S rRNA gene, batR, eno, ftsZ, gltA, groEL, $n l p D$, ribC, and rpoB. MLST sequences were assembled, processed and compared using BioNumerics 7.6 software (Applied Maths, Belgium), which identified alleles and sequence types based on published profiles [28]. Alleles were assigned 9-digit numerical codes and compared using the categorical coefficient and hierarchical clustering using the unweighted pair group method with arithmetic mean (UPGMA) method. MLST results were compared with sequence types (STs) in the B. henselae database (http://bhenselae.mlst.net/) [29].

At three days after inoculation, plates did not show visible colonies, although a few plates contained "shiny islets" suggestive of initial bacterial growth. At six days after inoculation, two TSA plates and one $\mathrm{BH}$ plate showed visible Bartonella-like colonies (Table 1). Upon subculturing onto two fresh TSA plates and one fresh $\mathrm{BH}$ plate, growth was visible on all three plates after four days, and it was abundant after six days (Table 1). A blood sample taken from the cat after doxycycline treatment did not give rise to bacterial growth even after one month of incubation.

PCR to amplify Bartonella spp. 16S rRNA and intergenic spacer regions was negative for DNA extracted from cat blood sampled before and after doxycycline treatment. Both types of PCR gave positive results when DNA was extracted from TSA and BH colonies cultured from the blood. Sequencing and BLAST analysis indicated B.henselae. The strain was genotyped by MLST and found to have the code 2-1-1-1-1-2-1-1-1, corresponding to genotype ST5 (Fig. 1).

\section{Discussion and conclusions}

Cat-scratch disease typically presents as regional lymphadenopathy in people with a history of cat contact, usually kittens [30]. The disease occurs more often in younger people with flea-infested cats younger than one year, and in people who have been scratched or bitten by a cat [4]. Cat-scratch disease causes regional, mainly unilateral, lymphadenopathy that localizes to the upper extremities on the injury side in immunocompetent patients [12], with 5-9\% of affected individuals developing atypical manifestations [4]. The patient in the present study fits this profile well. He had an anti- $B$. henselae titer of 1:512, while titers higher than 1:256 strongly suggest active or recent infection [12]. Noninfectious causes of lymph node enlargement, such as malignancy, were excluded [12], and azithromycin treatment proved effective for rapid resolution of lymphadenopathy $[12,30]$. Since the patient met basic criteria for the diagnoses of cat-scratch disease (lymphadenopathy, seropositivity, contact with cat and exclusion of malignancy), and since the cat was confirmed to be infected with Bartonella spp., no additional diagnostic procedures were performed. Molecular analysis of bacterial isolates and MLST-based genotyping indicated that the cat was infected with B. henselae. To our knowledge,

Table 1 Time course of growth of Bartonella spp. and PCR confirmation after blood of the infected cat was inoculated onto agar plates (primary culture) or subcultured (secondary culture)

\begin{tabular}{|c|c|c|c|c|c|c|}
\hline \multirow{2}{*}{$\begin{array}{l}\text { Plate } \\
\text { no. }\end{array}$} & \multirow[t]{2}{*}{ Agar } & \multirow[t]{2}{*}{ Culture } & \multicolumn{4}{|c|}{ Result after days of incubation } \\
\hline & & & 3 & 4 & 6 & 7 \\
\hline \multirow[t]{2}{*}{1} & TSA & Primary & Initial growth (SI) & & Visible growth & PCR+ \\
\hline & & Secondary & - & Initial growth & Visible growth & PCR+ \\
\hline \multirow[t]{2}{*}{2} & TSA & Primary & Initial growth (SI) & & Visible growth & PCR+ \\
\hline & & Secondary & - & Initial growth & Visible growth & PCR+ \\
\hline \multirow[t]{2}{*}{3} & $\mathrm{BH}$ & Primary & Initial growth (SI) & & Visible growth & $\mathrm{PCR}+$ \\
\hline & & Secondary & - & Initial growth & Visible growth & PCR+ \\
\hline \multirow[t]{2}{*}{4} & $\mathrm{BH}$ & Primary & Contaminated, discarded & - & - & - \\
\hline & & - & - & - & - & - \\
\hline
\end{tabular}




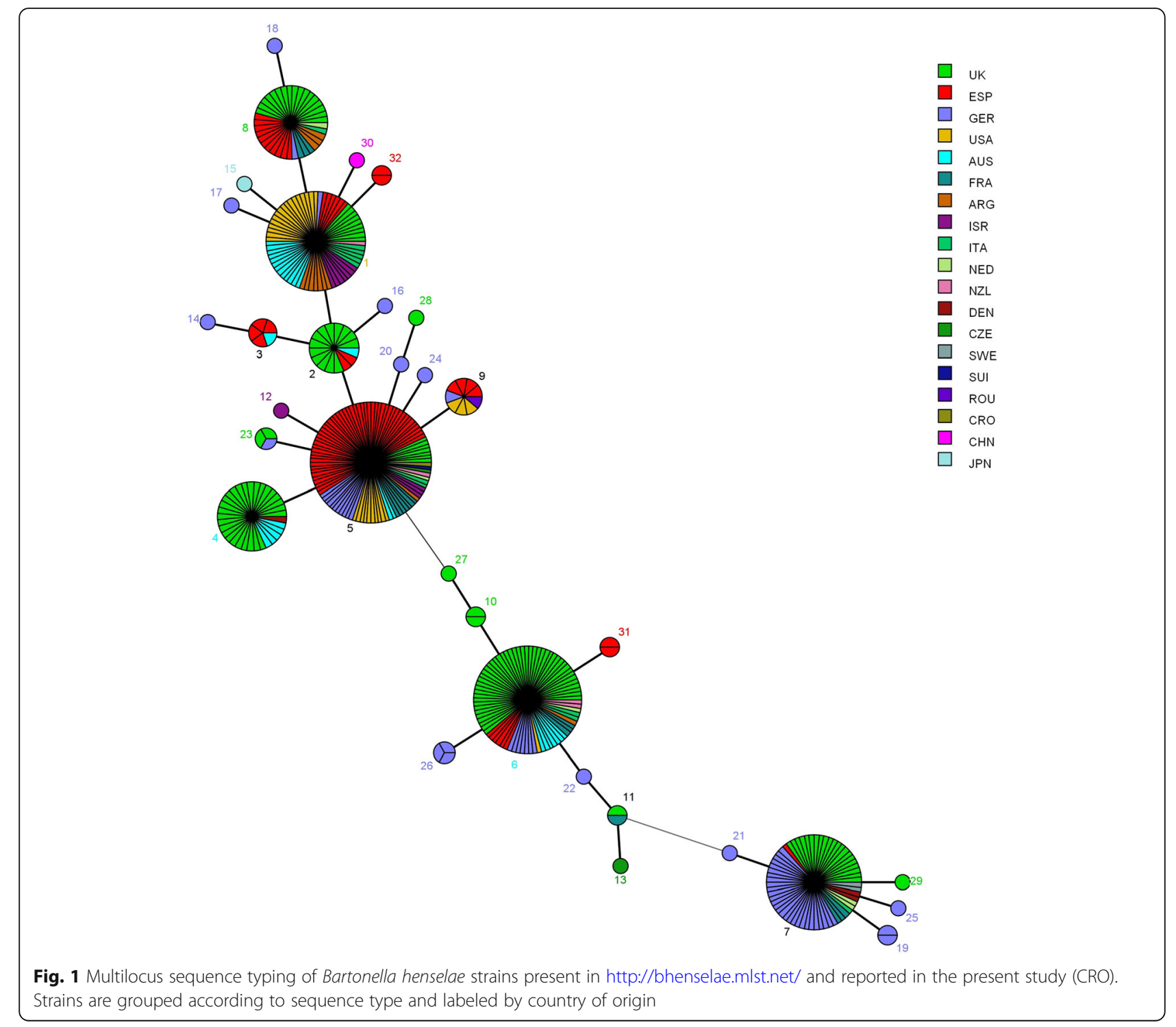

this is the first report of $B$. henselae culture from the blood of an infected cat in southeast Europe.

Our results confirm that although the genus Bartonella is fastidious and slow-growing, it can be cultured [31,32], even relatively rapidly: colonies became visible after 6 days in primary culture and after 4 days in subculture. In contrast, previous work reported that primary Bartonella colonies became visible as soon as $3-5$ days after plating but usually after $12-14$ days, sometimes 45 days [23, 33] or 56 days [31], while subcultured colonies appeared after 4-10 days [16], sometimes 15 days [33]. Other studies of Bartonella-like colonies from inoculated cat's blood have also reported slower first appearance than in our study, including 10-15 days on Columbia agar plates with $5 \%$ sheep blood [26], 1-2 weeks on Heart infusion agar with $10 \%$ rabbit blood [34], and 2 weeks (primary culture) or 5 days (subculture) on chocolate agar plates with 5\% defibrinated sheep blood [35]. In our study, primary $B$. henselae colonies were rough and adherent, and they pitted the agar. Upon subculture, they became larger, smooth and less adherent, as described previously $[33,36]$.

Our results suggest that direct blood culture is more sensitive than conventional PCR of whole blood for detecting $B$. henselae, similar to the conclusions of other authors [37]. Direct blood culture also appears to be preferable to IFA-based antibody detection because most flea-exposed cats develop anti-Bartonella antibodies, even when they are not bacteremic [38]. On the other hand, some studies have suggested that PCR, especially nested or real-time rather than conventional PCR, can be more sensitive than culturing $[16,34]$. Nevertheless, isolation by culture is encouraged for MLST genotyping because it enables broader molecular characterization 
and accurate species determination, and it proves that the isolate is living [16]. In the end, culture and PCR are complementary methods and so both should be used whenever possible $[15,16]$. Cats that serve as chronic subclinical reservoirs with cyclic bacteremia often give false negative results by PCR [22], probably due to the small number of bacteria in the sample [37], and this may explain our negative results in the present case. MLST indicated that our $B$. henselae strain belongs to the most widespread zoonotic sequence type, ST5. Together, ST2, ST5 and ST8 account for $85 \%$ of zoonosis-associated $B$. henselae strains, according to a sampling study in the UK [39]. ST5 accounted for $20.9 \%$ of $182 \mathrm{~B}$. henselae isolates from 12 countries on three continents, and it has been reported in humans and cats in Europe, the US and Australia [40]. MLST of 78 feline and 53 human isolates in Spain found that types ST5, ST6 and ST9 were associated with felines, while humans were most often infected with ST1, ST5 or ST8. ST5 in that study accounted for $53.7 \%$ of B. henselae infections in humans and $61.5 \%$ of infections in cats [41], suggesting that it is the predominant variant infecting felines and human beings. Our results support previous knowledge about global prevalence of zoonotic genotype $B$. henselae ST5.

The most frequent route of $B$. henselae transmission between cats is via the flea Ctenocephalides felis $[4,31]$ or their feces [13], in which bacteria can survive for at least nine days [14]. Flea control appears to be the only effective way to prevent infection of cats. Using antibiotics to treat clinically healthy cats infected with $B$. henselae is controversial, since bacteremia can persist for 22-33 weeks in experimentally infected cats [42-44]. Nevertheless, the cat in the present study was treated with doxycycline because she was bacteremic and because the owners requested it.

The present results show, for the first time, that zoonotic B.henselae strain ST5 is present in southeast Europe. Further studies are needed to investigate $B$. henselae prevalence in humans and cats, and correlation between isolates based on culturing and MLST. Our ability to detect $B$. henselae in blood through culturing but not PCR highlights the likely existence of infected cats with low bacteremia, suggesting the need to develop faster, more sensitive detection assays.

\footnotetext{
Abbreviations

16S rDNA: 165 ribosomal deoxyribonucleic acid; batR: Two-component regulator; $\mathrm{BH}$ : Brain heart agar; $\mathrm{CRP}$ : C-reactive protein; eno: enolase; ftsZ: Cell division protein; gltA: Citrate synthase; groEL: Hsp60 chaperone; IFA: Immunofluorescence assay; K2-EDTA: dipotassium ethylenediaminetetraacetic acid; MLST: multi-locus sequence typing; nlpD: Cell surface glycoprotein; PCR: polymerase chain reaction; ribC: Riboflavin synthase; rpoB: RNA polymerase beta subunit; SI: "shiny islet" incipient colonies; ST: Sequence type; TSA: Tryptic soy agar; UPGMA: Unweighted pair group method with arithmetic mean
}

\section{Acknowledgments}

The authors acknowledge Dr. Oktavija Đaković Rode from the University Hospital for Infectious Diseases "Dr Fran Mihaljević" (Zagreb, Croatia) for professional assistance.

\section{Funding}

This research was funded by GENOTICKTRECK of the Croatian Science Foundation (project no. 1957) and by the Croatian Veterinary Institute. Neither of these funders participated in study design; data collection, analysis, or interpretation; or manuscript writing.

\section{Availability of data and materials}

All data generated or analyzed during this study are included in this article or are available from the corresponding author on request.

\section{Authors' contributions}

RB and SS designed the study. MS and GK cultured B. henselae. SD and IR performed MLST and phylogeny analyses. All authors contributed to data acquisition, analysis and interpretation. MS and RB drafted the manuscript, which all authors proofread and approved to be published.

\section{Ethics approval and consent to participate}

Not applicable.

\section{Consent for publication}

The parents of the patient and owners of the cat in this study gave written informed consent for publication of their data.

\section{Competing interests}

The authors declare that they have no competing interests.

\section{Publisher's Note}

Springer Nature remains neutral with regard to jurisdictional claims in published maps and institutional affiliations.

Received: 27 April 2018 Accepted: 20 March 2019

Published online: 02 April 2019

\section{References}

1. Breitschwerd EB, Maggi RG, Chomel BB, Lappin MR. Bartonellosis: an emerging infectious disease of zoonotic importance to animals and human beings. J Vet Emerg Crit Care. 2010;20:8-30. https://doi.org/10. 1111/j.1476-4431.2009.00496.x.

2. Ridder-Schröter R, Marx A, Beer M, Tappe D, Kreth HW, Girschick HJ. Abscess-forming lymphadenopathy and osteomyelitis in children with Bartonella henselae infection. J Med Microbiol. 2008;57:519-24.

3. Manfredi R, Sabbatani S. Bartonellosis: suggestive case reports in adult and pediatric patients and therapeutic issues. Braz J Infect Dis. 2006;10:411-5.

4. Chomel BB, Boulouis HJ, Maruyama S, Breitschwerdt EB. Bartonella spp. in pets and effect on human health. Emerg Infect Dis. 2006;12:389-94.

5. Chomel BB, Kasten RW, Floyd-Hawkins K, Chi B, Yamamoto K, RobertsWilson J, et al. Experimental transmission of Bartonella henselae by the cat flea. J Clin Microbiol. 1996;34:1952-6.

6. Pandak N, Daković-Rode O, Cabraja I, Kristof Z, Kotarac S. Prevalence of Bartonella henselae antibodies in children and blood donors in Croatia. Infection. 2009;37:166-7.

7. Dzelalija B, Petrovec M, Avsic-Zupanc T. Probable atypical cat scratch disease presenting as isolated posterior pancreatic duodenal lymphadenitis and abdominal pain. Clin Infect Dis. 2001;33:912-4

8. Ledina D, Rincić J, Ivić I, Marasović D, Ledina D. A child with Bartonella henselae osteomyelitis of the right humerus. Acta Dermatovenerol Croat. 2004;12:92-5.

9. Vilibic-Cavlek T, Karlovic-Martinkovic D, Ljubin-Sternak S, Tabain I, Persic Z, Mlinaric-Galinovic G. High prevalence of Bartonella henselae and Bartonella quintana antibodies in Croatian patients presenting with lymphadenopathy Pol J Microbiol. 2012;61:315-7.

10. Hansmann $Y$, DeMartino S, Piémont $Y$, Meyer N, Mariet $P$, Heller $R$, et al. Diagnosis of cat scratch disease with detection of Bartonella henselae by PCR: a study of patients with lymph node enlargement. J Clin Microbiol. 2005;43:3800-6. 
11. Sander A, Posselt M, Böhm N, Ruess M, Altwegg M. Detection of Bartonella henselae DNA by two different PCR assays and determination of the genotypes of strains involved in histologically defined cat scratch disease. J Clin Microbiol. 1999:37:993-7.

12. Klotz SA, lanas V, Elliott SP. Cat-scratch disease. Am Fam Physician. 2011;83: 152-5.

13. Brunt J, Guptill L, Kordick DL, Kudrak S, Lappin MR. American association of feline practitioners 2006 panel report on diagnosis, treatment, and prevention of Bartonella spp. infections. J Feline Med Surg. 2006;8:213-26.

14. Pennisi MG, Marsilio F, Hartmann K, Lloret A, Addie D, Belák S, et al. Bartonella species infection in cats: $A B C D$ guidelines on prevention and management. J Feline Med Surg. 2013;15:563-9.

15. Fabbi M, De Giuli L, Tranquillo M, Bragoni R, Casiraghi M, Genchi C. Prevalence of Bartonella henselae in Italian stray cats: evaluation of serology to assess the risk of transmission of Bartonella to humans. J Clin Microbiol. 2004; $42: 264-8$

16. Gutierrez R, Vayssier-Taussat M, Buffet JP, Harrus S. Guidelines for the isolation, molecular detection, and characterization of Bartonella species. Vector borne zoonotic dis. 2017:17:42-50.

17. Breitschwerdt EB. Bartonellosis: one health perspectives for an emerging infectious disease. ILAR J. 2014:55:46-58.

18. Breitschwerdt EB. Leading off: Bartonellosis: clinical and diagnostic challenges. DVM360 (internet). 2010. Available from: http:// veterinarymedicine.dvm360.com.

19. Doern GV. Detection of selected fastidious bacteria. Clin Infect Dis. 2000;30: 166-73.

20. Lynch T, Iverson J, Kosoy M. Combining culture techniques for Bartonella: the best of both worlds. J Clin Microbiol. 2011;49:1363-8.

21. Ketring KL, Zuckerman EE, Hardy WD Jr. Bartonella: a new etiological agent of feline ocular disease. J Am Anim Hosp Assoc. 2004;40:6-12.

22. Lappin MR. Bartonella spp. infections in cats. AAHA (internet); 2009. p. 357-9. Available from: https://ams.aaha.org

23. Brenner SA, Rooney JA, Manzewitsch P, Regnery RL. Isolation of Bartonella (Rochalimaea) henselae: effects of methods of blood collection and handling. J Clin Microbiol. 1997;35:544-7.

24. Agan BK, Dolan MJ. Laboratory diagnosis of Bartonella infections. Clin Lab Med. 2002:22:937-62.

25. Maurin M, Birtles R, Raoult D. Current knowledge of Bartonella species. Eur J Clin Microbiol Infect Dis. 1997;16:487-506.

26. Pons I, Sanfeliu I, Quesada M, Anton E, Sampere M, Font B, et al. Prevalence of Bartonella henselae in cats in Catalonia, Spain. Am J Trop Med Hyg. 2005; 72:453-7.

27. Gil H, García-Esteban C, Barandika JF, Peig J, Toledo A, Escudero R, et al. Variability of Bartonella genotypes among small mammals in Spain. App Environ Microbiol. 2010;76:8062-70.

28. Iredell J, Blanckenberg D, Arvand M, Grauling S, Feil EJ, Birtles RJ. Characterization of the natural population of Bartonella henselae by multilocus sequence typing. J Clin Microbiol. 2003;41:5071-9.

29. MLST Bartonella henselae database. http://bhenselae.mlst.net/

30. Chondrogiannis K, Vezakis A, Derpapas M, Melemeni A, Fragulidis G. Seronegative cat-scratch disease diagnosed by PCR detection of Bartonella henselae DNA in lymph node samples. Braz J Infect Dis. 2012;16:96-9.

31. Breitschwerdt EB. Feline bartonellosis and cat scratch disease. Vet Immuno Immunopathol. 2008;123(1-2):167-71.

32. Chomel BB, Kasten RW. Bartonellosis, an increasingly recognized zoonosis. J Appl Microbiol. 2010;109:743-50.

33. Maurin M, Roux V, Stein A, Ferrier F, Viraben R, Raoult D. Isolation and characterization by immunofluorescence, sodium dodecyl sulfatepolyacrylamide gel electrophoresis, western blot, restriction fragment length polymorphism-PCR, 165 rRNA gene sequencing, and pulsed-field gel electrophoresis of Rochalimaea quintana from a patient with bacillary angiomatosis. J Clin Microbiol. 1994;32:1166-71.

34. Bai Y, Rizzo MF, Alvarez D, Moran D, Peruski LF, Kosoy M. Coexistence of Bartonella henselae and B. clarridgeiae in populations of cats and their fleas in Guatemala. J Vector Ecol. 2015;40:327-32.

35. Yanagihara M, Tsuneoka H, Hoshide S, Ishido E, Umeda A, Tsukahara M, et al. Molecular typing of Bartonella henselae DNA extracted from human clinical specimens and cat isolates in Japan. FEMS Immunol Med Microbiol. 2010;60:44-8.

36. Regnery RL, Anderson BE, Clarridge JE 3rd, Rodriquez-Barradas MC, Jones DC, Carr JH. Characterization of a novel Rochalimaea species, $R$. henselae sp. nov., isolated from blood of a febrile, human immunodeficiency viruspositive patient. J Clin Microbiol. 1992;30:265-74.

37. Fleischman DA, Chomel BB, Kasten RW, Stuckey MJ, Scarlet J, Liu H, et al. Bartonella infection among cats adopted from a San Francisco shelter, revisited. Appl Environ Microbiol. 2015;81:6446-50.

38. Chomel BB, Abbott RC, Kasten RW, Floyd-Hawkins KA, Kass PH, Glaser CA, et al. Bartonella henselae prevalence in domestic cats in California: risk factors and association between bacteremia and antibody titers. J Clin Microbiol. 1995:33:2445-50.

39. Chaloner GL, Harrison TG, Coyne KP, Aanensen DM, Birtles RJ. Multilocus sequence typing of Bartonella henselae in the United Kingdom indicates that only a few, uncommon sequence types are associated with zoonotic disease. J Clin Microbiol. 2011;49:2132-7.

40. Arvand M, Feil EJ, Giladi M, Boulouis HJ, Viezens J. Multi-locus sequence typing of Bartonella henselae isolates from three continents reveals hypervirulent and feline-associated clones. PLoS One. 2007;2(12):e1346.

41. Gil H, Escudero R, Pons I, Rodríguez-Vargas M, García-Esteban C, RodríguezMoreno I, et al. Distribution of Bartonella henselae variants in patients, reservoir hosts and vectors in Spain. PLoS One. 2013;8(7):e68248.

42. Yamamoto K, Chomel BB, Kasten RW, Hew CM, Weber DK, Lee WI. Experimental infection of specific pathogen free (SPF) cats with two different strains of Bartonella henselae type I: a comparative study. Vet Res. 2002;33:669-84.

43. O'Reilly KL, Bauer RW, Freeland RL, Foil LD, Hughes KJ, Rohde KR, et al. Acute clinical disease in cats following infection with a pathogenic strain of Bartonella henselae (LSU16). Infect Immun. 1999;67:3066-72.

44. Guptill L, Slater L, Wu CC, Lin TL, Glickman LT, Welch DF, et al. Experimental infection of young specific pathogen-free cats with Bartonella henselae. J Infect Dis. 1997:176:206-16.

\section{Ready to submit your research? Choose BMC and benefit from:}

- fast, convenient online submission

- thorough peer review by experienced researchers in your field

- rapid publication on acceptance

- support for research data, including large and complex data types

- gold Open Access which fosters wider collaboration and increased citations

- maximum visibility for your research: over $100 \mathrm{M}$ website views per year

At $\mathrm{BMC}$, research is always in progress.

Learn more biomedcentral.com/submissions 